\title{
Modeling, Analysis, and Neural Network Control of an EV Electrical Differential
}

\author{
Abdelhakim Haddoun, Mohamed El Hachemi Benbouzid, Senior Member, IEEE, \\ Demba Diallo, Senior Member, IEEE, Rachid Abdessemed, Jamel Ghouili, and Kamel Srairi
}

\begin{abstract}
This paper presents system modeling, analysis, and simulation of an electric vehicle (EV) with two independent rear wheel drives. The traction control system is designed to guarantee the EV dynamics and stability when there are no differential gears. Using two in-wheel electric motors makes it possible to have torque and speed control in each wheel. This control level improves EV stability and safety. The proposed traction control system uses the vehicle speed, which is different from wheel speed characterized by a slip in the driving mode, as an input. In this case, a generalized neural network algorithm is proposed to estimate the vehicle speed. The analysis and simulations lead to the conclusion that the proposed system is feasible. Simulation results on a test vehicle propelled by two $37-\mathrm{kW}$ induction motors showed that the proposed control approach operates satisfactorily.
\end{abstract}

Index Terms-Electric vehicle (EV), induction motor, neural networks, speed estimation, traction control.

\section{INTRODUCTION}

$\mathbf{R}$ ECENTLY, electric vehicles (EVs), including fuel-cell and hybrid vehicles, have been developed very rapidly as a solution to energy and environmental problems. From the point of view of control engineering, EVs have much attractive potential. Since electric motors and inverters are utilized in drive systems, they have great advantages over internal combustion engine vehicles such as quick torque response and individual control of each wheel [1], [2]. Although several control methods have been proposed using these merits, their controllers depend on some immeasurable parameters, including vehicle velocity and slip angle [3].

Generally, in most EV propulsion applications, an ac motor is connected to the wheels by reduction gears and mechanical differential. In some vehicle drive arrangements, high-speed low-torque wheel motors requiring gear reduction are used. In

Manuscript received April 17, 2007; revised November 8, 2007

A. Haddoun is with the Laboratoire Brestois de Mécanique et des Systèmes, University of Western Brittany, 29238 Brest, France, and also with the University of Oum El Bouaghi, 04000 Oum El Bouaghi, Algeria.

M. E. H. Benbouzid is with the Laboratoire Brestois de Mecanique et des Systemes, University of Western Brittany, 29238 Brest, France (e-mail: m.benbouzid@ieee.org).

D. Diallo is with the Laboratoire de Génie Electrique de Paris (LGEP/SPEE labs), CNRS UMR 8507, Supélec; University Pierre and Marie Curie P6; University of Paris Sud P11, 91192 Gif-Sur-Yvette, France (e-mail: ddiallo@ ieee.org).

R. Abdessemed is with the University of Batna, 05000 Batna, Algeria.

J. Ghouili is with the GRET Research Group, Engineering Faculty, University of Moncton, Moncton, NB E1A 3E9, Canada.

K. Srairi is with the University of Biskra, 07000 Biskra, Algeria.

Color versions of one or more of the figures in this paper are available online at http://ieeexplore.ieee.org.

Digital Object Identifier 10.1109/TIE.2008.918392 these cases, either a gear motor assembly is mounted inside the wheel or a chassis-mounted motor is connected to the wheel through gear reduction.

Further simplification of the vehicle drive arrangement results in elimination of the gear being interposed between the motor and wheel. The condition above calls for the use of an electric differential (no mechanical gear) [4]-[7]. Electric differential-based EVs have advantages over their classical counterparts with a central motor. Indeed, mounting the motors directly on the wheels simplifies the mechanical layout. The electric differential system will reduce the drive line components, thus improving the overall reliability and efficiency. This option will also reduce the drive line weight since mechanical differential and gear reduction are not used [6]-[8]. However, one of the main issues in the design of these EVs (without mechanical differential) is how to ensure the vehicle stability. During normal driving conditions, all drive wheel systems require a symmetrical distribution of torque on both sides. This symmetrical distribution is not sufficient when the adherence coefficient of tires is changing; the wheels have different speeds, hence the need for traction control systems [4]. This is still an open problem as illustrated by the limited availability of literature [10]-[12].

This paper proposes a neural network traction control approach of an electrical differential system for an EV propelled by two induction motor drives (one for each rear wheel) [13]. Indeed, neural network concepts have become an active research area in power electronics and motor drives. Because of the necessity for adaptive abilities in a network learning process, applying neural networks to system identification and control dynamics has become a promising alternative to process control. Neural networks can be applied to control and identify nonlinear systems since they approximate any desired degree of accuracy with a wide range of nonlinear models [14]-[20].

The rotor speed information of an induction motor in the vector control method is obtained using speed sensors. Since these sensors are usually expensive and bulky, the cost and size of the drive systems are increased. Since the 1980s the concept of rotor speed estimation has been studied extensively. The instantaneous stator voltages and currents were used to estimate the speed of an induction motor, such as in model reference adaptive systems and extended Kalman filter algorithms. However, induction motors have highly nonlinear dynamic behavior and their parameters vary with time and operating conditions. Therefore, it is difficult to obtain accurate speed estimates with these methods. In this paper, a practical speed estimation method for an induction motor is proposed where a 
recurrent neural network (RNN) with two hidden layers is used [21]-[23]. In fact, the RNN used is called the Elman neural network (ENN) [23]. The ENN multilayer and recurrent structure makes it robust under parameter variations and system noises. Moreover, the proposed RNN-based speed estimator, which replaces the speed sensor in the control approach scheme, takes into account vehicle aerodynamics and is not applied to sole induction motors. It should be noted that the induction motor was adopted because it seems to be the candidate that best fulfils the major requirements for EV propulsion [24]-[26].

\section{VEHICLE MODEL}

\section{A. Nomenclature}

$v \quad$ Vehicle speed.

a Vehicle acceleration.

$m \quad$ Vehicle mass.

$\alpha \quad$ Grade angle.

$F_{\text {te }} \quad$ Tractive force.

$F_{\text {rr }} \quad$ Rolling resistance force.

$F_{\text {hc }} \quad$ Hill climbing force.

$F_{\text {la }} \quad$ Linear acceleration force.

$F_{\text {wa }}$ Angular acceleration force.

$T_{\mathrm{m}} \quad$ Motor torque.

$P_{\text {te }} \quad$ Vehicle driving power.

$J \quad$ Total inertia (rotor and load).

$G \quad$ Gear ratio.

$\eta_{\mathrm{g}} \quad$ Gear system efficiency.

$r \quad$ Tire radius.

\section{B. Dynamics Analysis}

Compared to previous work, the proposed control strategy takes into account vehicle aerodynamics and is not applied to sole induction motors. This model is based on the principles of vehicle mechanics and aerodynamics [7]. The total tractive effort is then given by

$$
F_{\text {te }}=F_{\text {rr }}+F_{\text {ad }}+F_{\text {hc }}+F_{\text {la }}+F_{\text {wa }} .
$$

This is the force propelling the vehicle forward and transmitted to the ground through the wheels (Fig. 1).

$F_{\text {la }}$ and $F_{\text {wa }}$ have been added in this paper for a more accurate representation of the needed force to accelerate the vehicle. Indeed, we should consider linear acceleration as well as rotational acceleration. The main issue here is the electric motor, not necessarily because of its particularly high moment of inertia, but because of its higher angular speeds [27]. It should be noted that $F_{\mathrm{la}}$ and $F_{\mathrm{wa}}$ will be negative if the vehicle is slowing down and that $F_{\mathrm{hc}}$ will be negative if it is going downhill. Therefore, the motor torque required for an angular acceleration will be given by

$$
T_{\mathrm{m}}=\frac{J G}{\eta_{\mathrm{g}} r} a .
$$

Finally, the power required to drive a vehicle at a speed $v$ has to compensate for counteracting forces

$$
P_{\mathrm{te}}=v F_{\mathrm{te}}=v\left(F_{\mathrm{rr}}+F_{\mathrm{ad}}+F_{\mathrm{hc}}+F_{\mathrm{la}}+F_{\mathrm{wa}}\right) .
$$

\section{InduCtion Motor ModELING}

\section{A. Nomenclature}

$V_{\mathrm{ds}}\left(V_{\mathrm{qs}}\right) \quad d$-axis ( $q$-axis) stator voltages.

$i_{\mathrm{ds}}\left(i_{\mathrm{qs}}\right) \quad d$-axis ( $q$-axis) stator currents.

$\lambda_{\mathrm{dr}}\left(\lambda_{\mathrm{qr}}\right) \quad d$-axis ( $q$-axis) rotor flux linkages.

$T_{\mathrm{L}} \quad$ Load torque.

$R_{\mathrm{S}}\left(R_{\mathrm{r}}\right) \quad$ Stator (rotor) resistance.

$L_{\mathrm{S}}\left(L_{\mathrm{r}}\right) \quad$ Stator (rotor) inductance.

$L_{\mathrm{m}} \quad$ Magnetizing inductance.

$L_{\sigma} \quad$ Leakage inductance $\left(L_{\sigma}=L_{\mathrm{s}}-L_{\mathrm{m}}^{2} / L_{\mathrm{r}}\right)$.

$\omega_{\mathrm{e}}\left(\omega_{\mathrm{r}}\right) \quad$ Stator (rotor) electrical speed.

$\Omega \quad$ Rotor speed $\left(\omega_{\mathrm{r}} / p\right)$.

$\omega_{\mathrm{sl}} \quad$ Slip frequency, $\omega_{\mathrm{sl}}=\omega_{\mathrm{e}}-\omega_{\mathrm{r}}$.

$B \quad$ Motor damping ratio.

$p \quad$ Pole-pair number.

$$
\left\{\begin{array}{l}
k_{1}=\frac{R_{\mathrm{s}}}{L_{\sigma}}+\frac{R_{\mathrm{r}} L_{\mathrm{m}}^{2}}{L_{\mathrm{r}}^{2} L_{\sigma}}, k_{2}=\frac{R_{\mathrm{r}} L_{\mathrm{m}}}{L_{\mathrm{r}}^{2} L_{\sigma}}, k_{3}=\frac{L_{\mathrm{m}}}{L_{\mathrm{r}} L_{\sigma}}, \\
k_{4}=\frac{R_{\mathrm{r}} L_{\mathrm{m}}}{L_{\mathrm{r}}}, k_{5}=\frac{R_{\mathrm{r}}}{L_{\mathrm{r}}}, k_{6}=\frac{1}{L_{\sigma}}, k_{t}=\frac{3}{2} p \frac{L_{\mathrm{m}}}{L_{\mathrm{r}}} .
\end{array}\right.
$$

\section{B. Induction Motor Dynamic Model}

Generally, dynamic modeling of an induction motor drive is based on rotating reference-frame theory and a linear technique. A system configuration of an induction motor drive is shown in Fig. 2 (taking into account the vehicle dynamics). This motor drive consists of an induction motor, a bang-bang currentcontrolled pulsewidth modulated inverter, a field-orientation mechanism, a coordinate translator and a speed controller. The electrical dynamics of an induction motor in the synchronously rotating reference frame ( $d-q$ axis) can be expressed by [28]

$$
\begin{aligned}
\frac{d}{d t}\left[\begin{array}{c}
i_{\mathrm{ds}} \\
i_{\mathrm{qs}} \\
\lambda_{\mathrm{dr}} \\
\lambda_{\mathrm{qr}}
\end{array}\right]= & {\left[\begin{array}{cccc}
-k_{1} & \omega_{\mathrm{e}} & k_{2} & \omega_{\mathrm{r}} k_{3} \\
-\omega_{\mathrm{e}} & -k_{1} & -\omega_{\mathrm{r}} k_{3} & k_{2} \\
k_{4} & 0 & -k_{5} & \omega_{\mathrm{sl}} \\
0 & k_{4} & -\omega_{\mathrm{sl}} & -k_{5}
\end{array}\right]\left[\begin{array}{c}
i_{\mathrm{ds}} \\
i_{\mathrm{qs}} \\
\lambda_{\mathrm{dr}} \\
\lambda_{\mathrm{qr}}
\end{array}\right] } \\
& +k_{6}\left[\begin{array}{c}
V_{\mathrm{ds}} \\
V_{\mathrm{qs}} \\
0 \\
0
\end{array}\right] \\
\frac{d \omega_{\mathrm{r}}}{d t}= & -\frac{B}{J} \omega_{\mathrm{r}}-\frac{1}{J}\left(T_{\mathrm{m}}-T_{\mathrm{L}}\right) \\
T_{\mathrm{m}}= & k_{t}\left(\lambda_{\mathrm{dr}} i_{\mathrm{qs}}-\lambda_{\mathrm{qr}} i_{\mathrm{ds}}\right) .
\end{aligned}
$$

\section{Neural Network Traction Control}

\section{A. Why Neural Network Traction Control?}

Recent developments in artificial neural network (ANN) control technology have made it possible to train an ANN to represent a variety of complicated nonlinear systems [14]. ANN is a simulation of the human brain and nervous system built of artificial neurons and their interconnections. The ANN can be trained to solve the most complex nonlinear problems with variable parameters similar to the human brain. There have been 


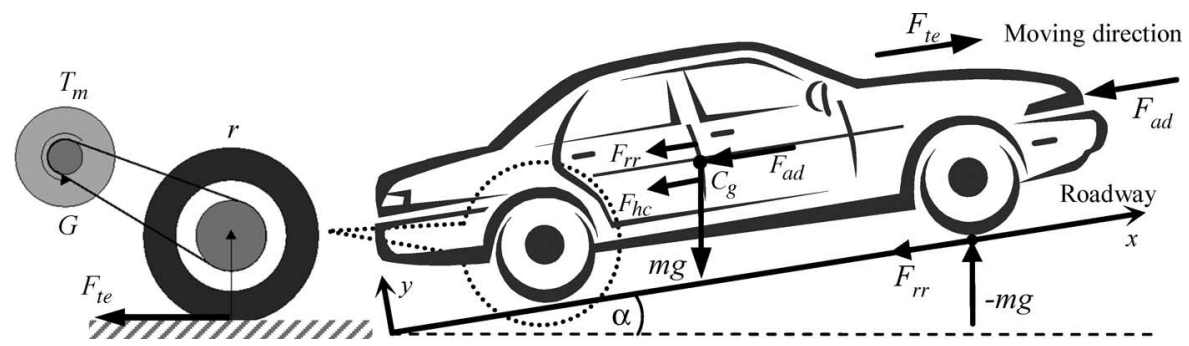

Fig. 1. Elementary forces acting on a vehicle.

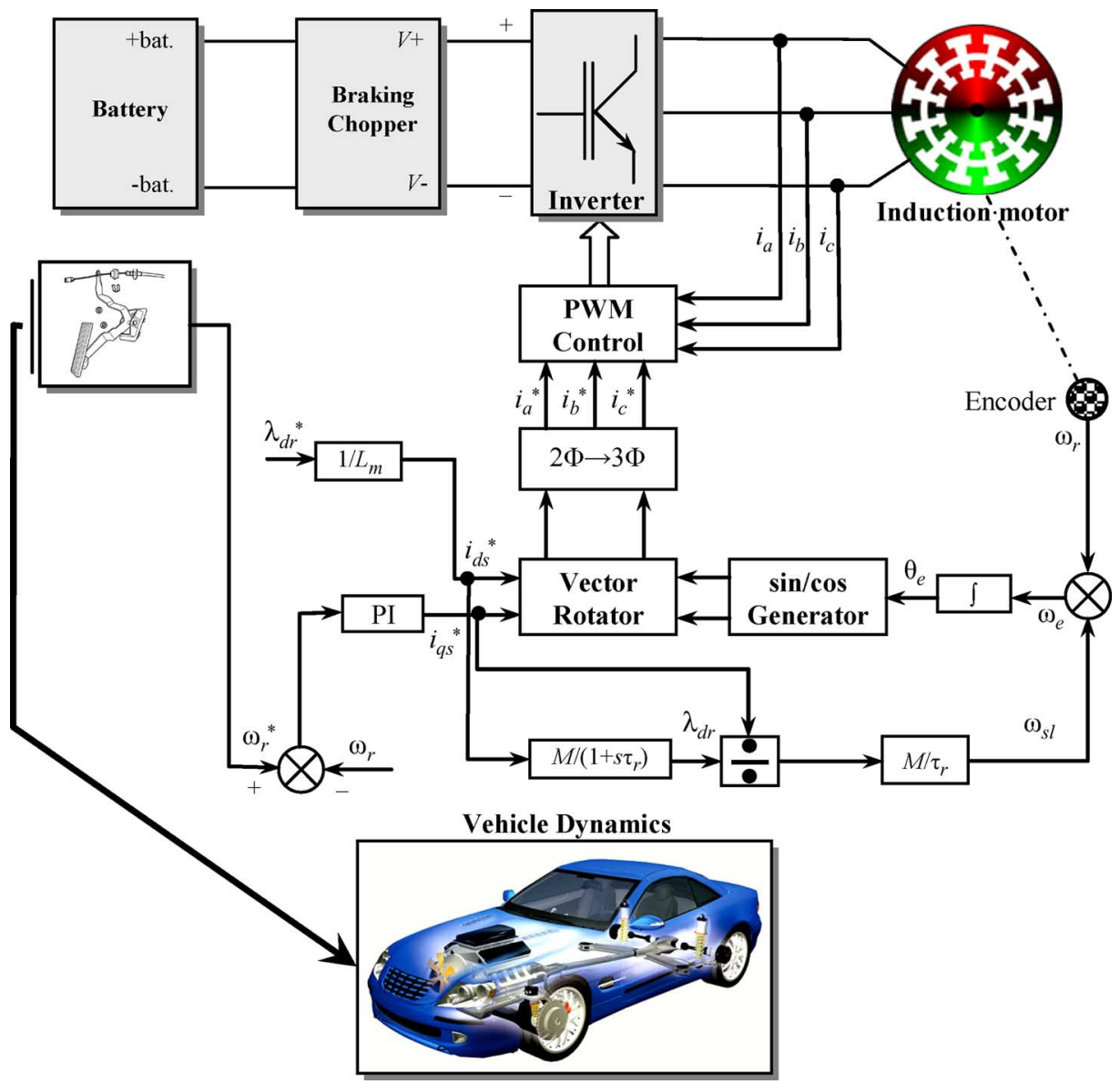

Fig. 2. Direct field-oriented induction motor drive.

several applications of ANN to induction motor drive systems such as adaptive flux control, current control, speed control, and field-oriented control [15]-[17].

\section{B. Neural Network Controller}

The dynamic behavior of an induction motor can be described by voltage and current models (with decoupling control $\lambda_{\mathrm{qr}}=0$ and $\lambda_{\mathrm{dr}}=\lambda=$ constant) are derived from (4)-(6)

$$
\left\{\begin{array}{l}
\frac{d i_{\mathrm{ds}}}{d t}=-k_{1} i_{\mathrm{ds}}+\omega_{\mathrm{e}} i_{\mathrm{qs}}+k_{2} \lambda_{\mathrm{dr}}+k_{6} V_{\mathrm{ds}} \\
\frac{d i_{\mathrm{qs}}}{d t}=-k_{1} i_{\mathrm{qs}}-\omega_{\mathrm{e}} i_{\mathrm{ds}}-k_{2} \lambda_{\mathrm{dr}}+k_{6} V_{\mathrm{qs}} \\
\frac{d \lambda_{\mathrm{dr}}}{d t}=-k_{5} \lambda_{\mathrm{dr}}+k_{4} i_{\mathrm{ds}} \\
T_{\mathrm{e}}=k_{t} \lambda_{\mathrm{dr}} i_{\mathrm{qs}} .
\end{array}\right.
$$

The RNN model-based speed estimator replaces the adaptive current model. In this case, each output neuron uses the linear activation function. The solution of the voltage model generates the desired flux components. These signals are compared with the RNN output signals and the weights are trained online so that the error $\xi(k+1)$ tends to zero. It is assumed that the training speed is fast enough so that the estimated speed and actual speed can track well [23].

The current model equations can be discretized and written as

$$
\begin{aligned}
{\left[\begin{array}{c}
\lambda_{\mathrm{dr}}^{s}(k+1) \\
\lambda_{\mathrm{qr}}^{s}(k+1)
\end{array}\right]=\left[\begin{array}{cc}
1-\frac{T_{\mathrm{s}}}{T_{\mathrm{r}}} & -\omega_{\mathrm{r}} T_{\mathrm{s}} \\
\omega_{\mathrm{r}} T_{\mathrm{s}} & 1-\frac{T_{\mathrm{s}}}{T_{\mathrm{r}}}
\end{array}\right]\left[\begin{array}{c}
\lambda_{\mathrm{dr}}^{s}(k) \\
\lambda_{\mathrm{qr}}^{s}(k)
\end{array}\right] } \\
+\left[\begin{array}{cc}
\frac{L_{\mathrm{m}} T_{\mathrm{s}}}{T_{\mathrm{r}}} & 0 \\
0 & \frac{L_{\mathrm{m}} T_{\mathrm{s}}}{T_{\mathrm{r}}}
\end{array}\right]\left[\begin{array}{l}
i_{\mathrm{ds}}^{s}(k) \\
i_{\mathrm{qs}}^{s}(k)
\end{array}\right]
\end{aligned}
$$

where $T_{\mathrm{s}}$ is the sampling time, $L_{\mathrm{m}}$ the magnetizing inductance, and $T_{\mathrm{r}}$ the rotor time constant. The above equation can also be 


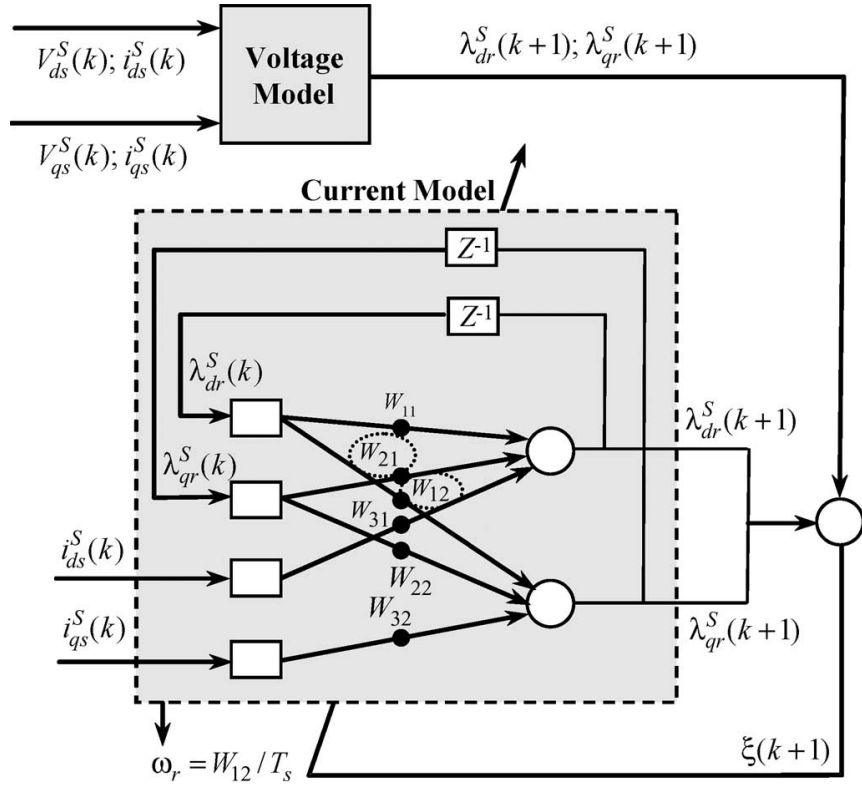

Fig. 3. Internal structure of the RNN estimator.

written in the form

$$
\begin{aligned}
{\left[\begin{array}{l}
\lambda_{\mathrm{dr}}^{s}(k+1) \\
\lambda_{\mathrm{qr}}^{s}(k+1)
\end{array}\right]=\left[\begin{array}{ll}
W_{11} & W_{21} \\
W_{12} & W_{22}
\end{array}\right]\left[\begin{array}{c}
\lambda_{\mathrm{dr}}^{s}(k) \\
\lambda_{\mathrm{qr}}^{s}(k)
\end{array}\right] } \\
+\left[\begin{array}{cc}
W_{31} & 0 \\
0 & W_{32}
\end{array}\right]\left[\begin{array}{l}
i_{\mathrm{ds}}^{s}(k) \\
i_{\mathrm{qs}}^{s}(k)
\end{array}\right]
\end{aligned}
$$

where $W_{11}=1-T_{\mathrm{s}} / T_{\mathrm{r}}, W_{21}=-\omega_{\mathrm{r}} T_{\mathrm{s}}, W_{12}=\omega_{\mathrm{r}} T_{\mathrm{s}}, W_{22}=$ $1-T_{\mathrm{s}} / T_{\mathrm{r}}$, and $W_{31}=W_{32}=L_{\mathrm{m}} T_{\mathrm{s}} / T_{\mathrm{r}}$.

The internal structure of the designed RNN speed estimator is shown in Fig. 3, where black circles represent context nodes and white circles represent the input, hidden and output nodes [12], [23]. The RNN with a linear transfer function of unity gain satisfies (9). Note that out of the six weights in the network, only $W_{21}$ and $W_{12}$ (circled in the figure) contain the speed term. Therefore, it is sufficient if these weights are considered trainable, keeping the other weights constant (assuming that $T_{\mathrm{r}}$ and $L_{\mathrm{m}}$ are constants) for speed estimation. However, if all the weights are considered trainable, the speed as well as the rotor time constant can be tuned.

\section{ELECTRIC DifFERENTIAL AND ITS IMPLEMENTATION}

Fig. 4 illustrates the implemented system (electric and mechanical components) in the Matlab-Simulink environment. It should be noted that the two inverters share the same dc bus whose voltage is supposed to be stable. Regenerative braking is not taken into account in this paper.

The proposed control system principle could be summarized as follows: 1) A speed network control is used to control each motor torque; 2) The speed of each rear wheel is controlled using speed difference feedback. Since the two rear wheels are directly driven by two separate motors, the speed of the outer wheel will need to be higher than the speed of the inner wheel during steering maneuvers (and vice-versa). This condition can be easily met if the speed estimator is used to sense the angular speed of the steering wheel. The common reference speed $\omega_{\text {ref }}$ is then set by the accelerator pedal command. The actual reference speed for the left drive $\omega_{\text {ref-left }}$ and the right drive $\omega_{\text {ref-right }}$ are then obtained by adjusting the common reference speed $\omega_{\text {ref }}$ using the output signal from the RNN speed estimator. If the vehicle is turning right, the left wheel speed is increased and the right wheel speed remains equal to the common reference speed $\omega_{\text {ref }}$. If the vehicle is turning left, the right wheel speed is increased and the left wheel speed remains equal to the common reference speed $\omega_{\text {ref }}$ [7].

Usually, a driving trajectory is adequate for an analysis of the vehicle system model. We therefore adopted the Ackermann-Jeantaud steering model, as it is widely used as a driving trajectory. In fact, the Ackermann steering geometry is a geometric arrangement of linkages in the steering system of a car or other vehicles designed to solve the problem of wheels on the inside and outside of a turn needing to trace out circles of different radii. Modern cars do not use pure Ackermann-Jeantaud steering, partly because it ignores important dynamic and compliant effects, but the principle is sound for low speed maneuvers [29]. It is illustrated in Fig. 5.

From this model, the following characteristic can be calculated:

$$
R=\frac{L}{\tan \delta}
$$

where $\delta$ is the steering angle. Therefore, the linear speed of each wheel drive is given by

$$
\left\{\begin{array}{l}
V_{1}=\omega_{\mathrm{V}}(R-d / 2) \\
V_{2}=\omega_{\mathrm{V}}(R+d / 2)
\end{array}\right.
$$

and their angular speed by

$$
\left\{\begin{array}{l}
\omega_{\text {est } 1}=\frac{L-(d / 2) \tan \delta}{L} \omega_{\mathrm{V}} \\
\omega_{\text {est } 2}=\frac{L+(d / 2) \tan \delta}{L} \omega_{\mathrm{V}}
\end{array}\right.
$$

where $\omega_{V}$ is the vehicle angular speed according to the center of turn.

The difference between wheel drive angular speeds is then

$$
\Delta \omega=\omega_{\text {est } 1}-\omega_{\text {est } 2}=-\frac{d \tan \delta}{L} \omega_{\mathrm{V}}
$$

and the steering angle indicates the trajectory direction

$$
\left\{\begin{array}{l}
\delta>0 \Rightarrow \text { Turn left } \\
\delta=0 \Rightarrow \text { Straight ahead } \\
\delta<0 \Rightarrow \text { Turn right. }
\end{array}\right.
$$

In accordance with the above described equation, Fig. 6 shows the electric differential system block diagram as used for simulations, where $K_{1}=1 / 2$ and $K_{2}=-1 / 2$.

\section{Simulation Results}

\section{A. RNN Control Strategy Tests}

Numerical simulations were carried out on an EV propelled by two $37-\mathrm{kW}$ induction motor drives whose ratings are 


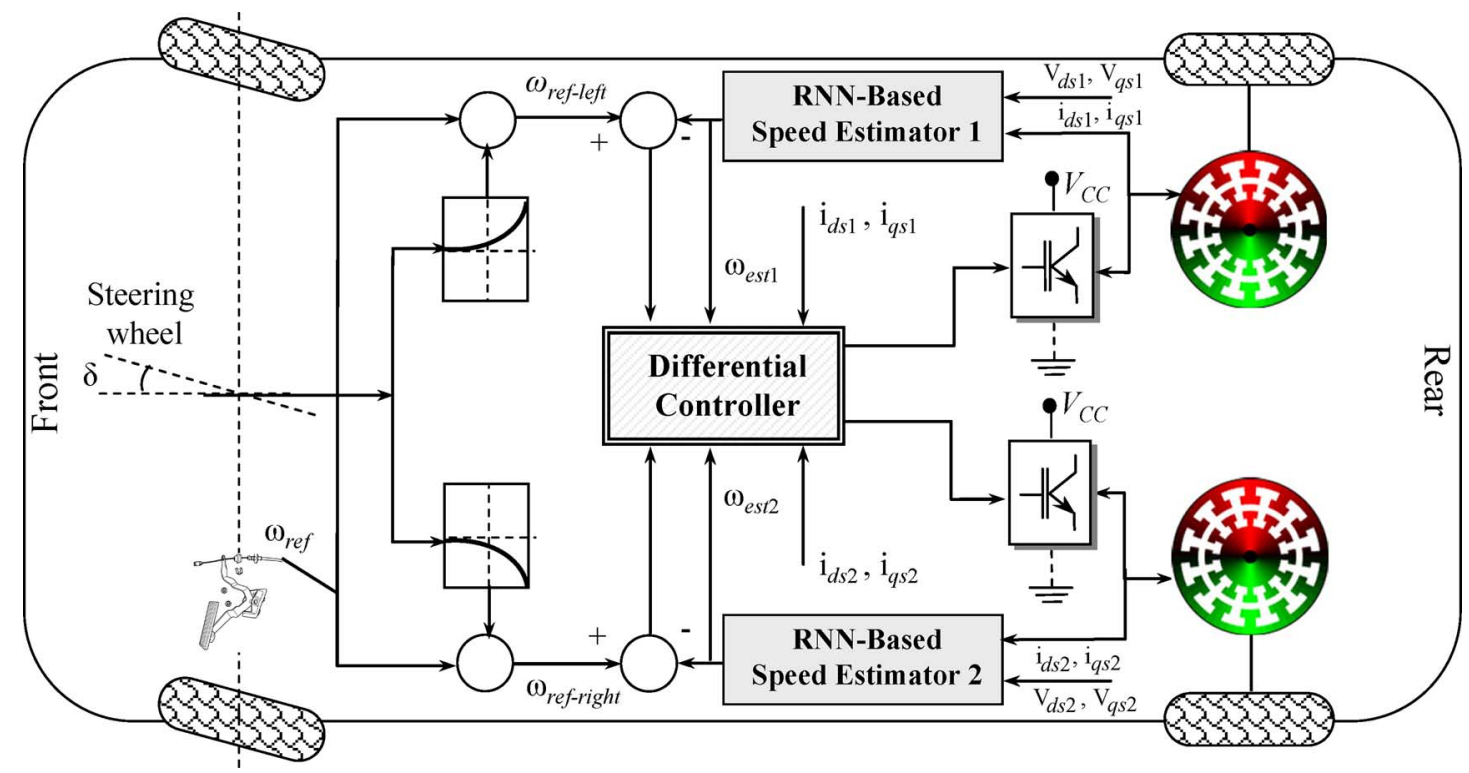

Fig. 4. EV propulsion and control systems schematic diagram.

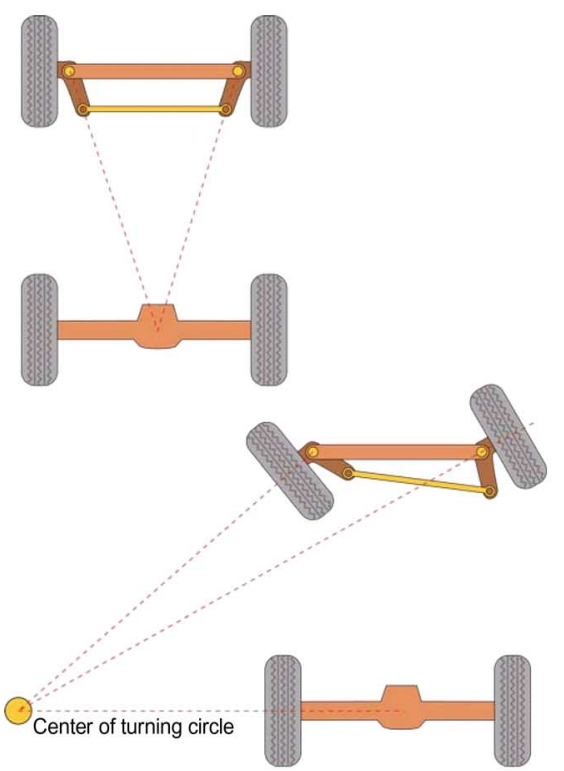

Fig. 5. Driving trajectory model.

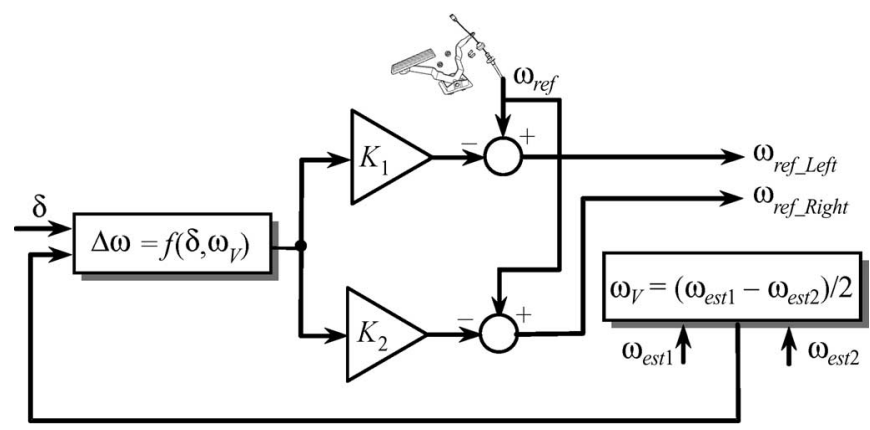

Fig. 6. Block diagram of the electric differential system.

summarized in the Appendix (Fig. 7). Electrical vehicle mechanical and aerodynamic characteristics are also given in the Appendix. Objectives of the simulations carried out were to assess the efficiency and dynamic performance of the proposed neural network control strategy.

The test cycle is the urban ECE-15 cycle (Fig. 8) [30]. A driving cycle is a series of data points representing the vehicle speed versus time. It is characterized by low vehicle speed (maximum $50 \mathrm{~km} / \mathrm{h}$ ) and is useful for testing electrical vehicle performance in urban areas.

The electric differential performances are first illustrated by Fig. 9, which shows each wheel's drive speed during steering for $0<t<1180 \mathrm{~s}$. It is obvious that the electric differential operates satisfactorily according to the complicated series of accelerations, decelerations, and frequent stops imposed by the urban ECE-15 cycle.

Figs. 10 and 11 illustrate the EV dynamics, respectively, the flux $\left(\lambda_{\mathrm{dr}}\right)$ and the developed torque in each induction motor on the left and right wheel drives, with changes in the acceleration 


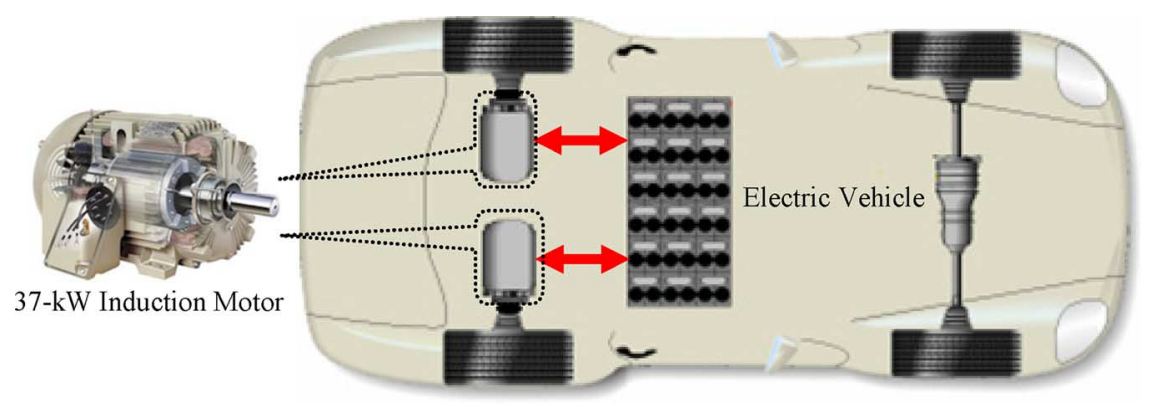

Fig. 7. Simulated system.

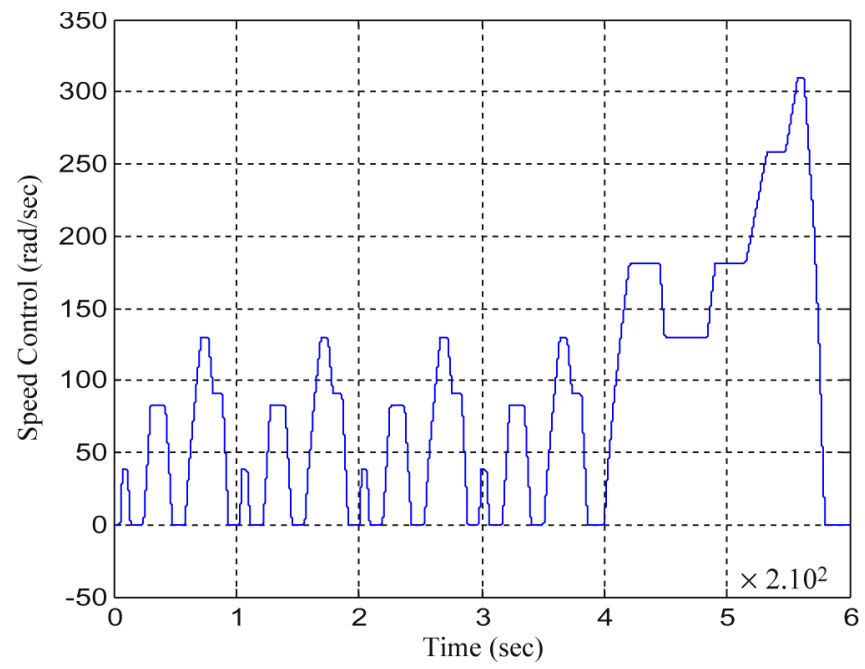

Fig. 8. European urban driving schedule ECE-15.

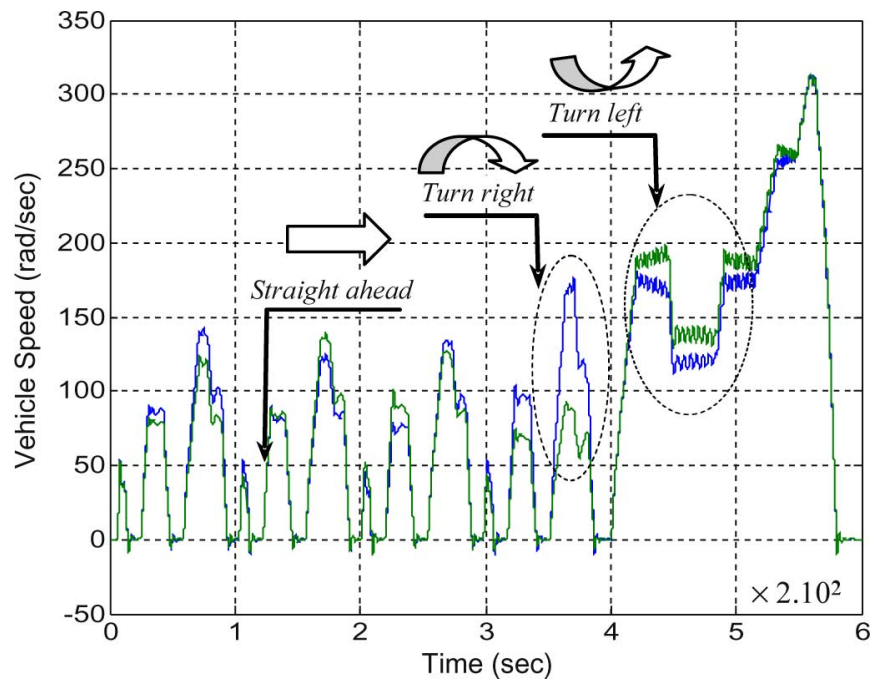

Fig. 9. Vehicle wheels speed.

pedal position (Fig. 12) and a varied road profile (rising and downward portions). It should be noticed that flux and torque variations are as large as variations of the accelerator pedal and the road profile.

The RNN speed estimator performances are illustrated by Fig. 13, which shows the measured speed and the estimated value. This figure clearly shows that the estimated speed during this test correctly follows the measured one even at zero-speed.

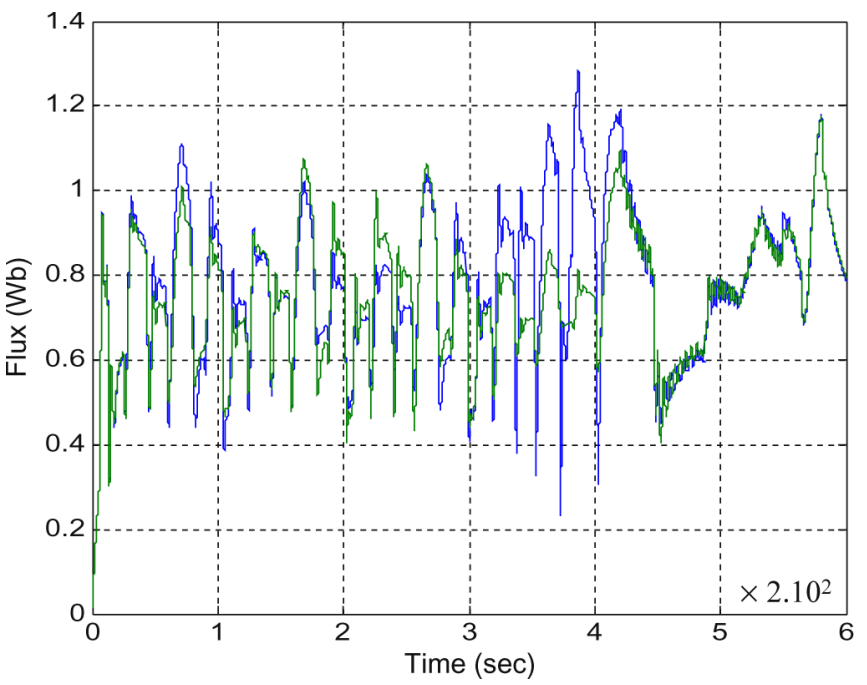

Fig. 10. Flux $\lambda_{\mathrm{dr}}$.

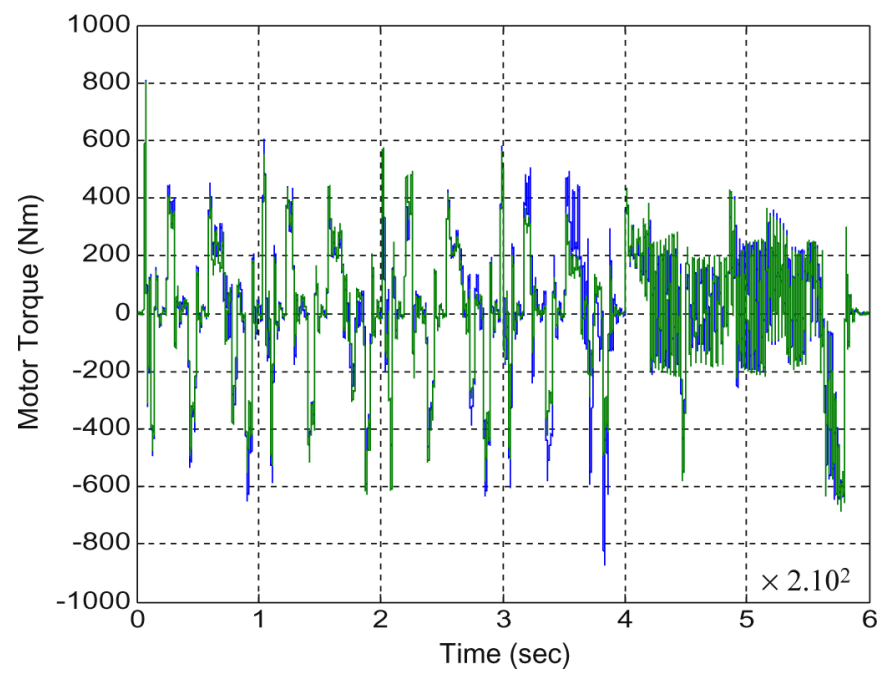

Fig. 11. Motor torque.

This was not the case in [31], where the estimation failed around zero-speed especially at no-load.

Fig. 14 illustrates the power required to move the EV. To find the power taken from the battery to provide the tractive effort, we have to be able to find various efficiencies at all operating points. 


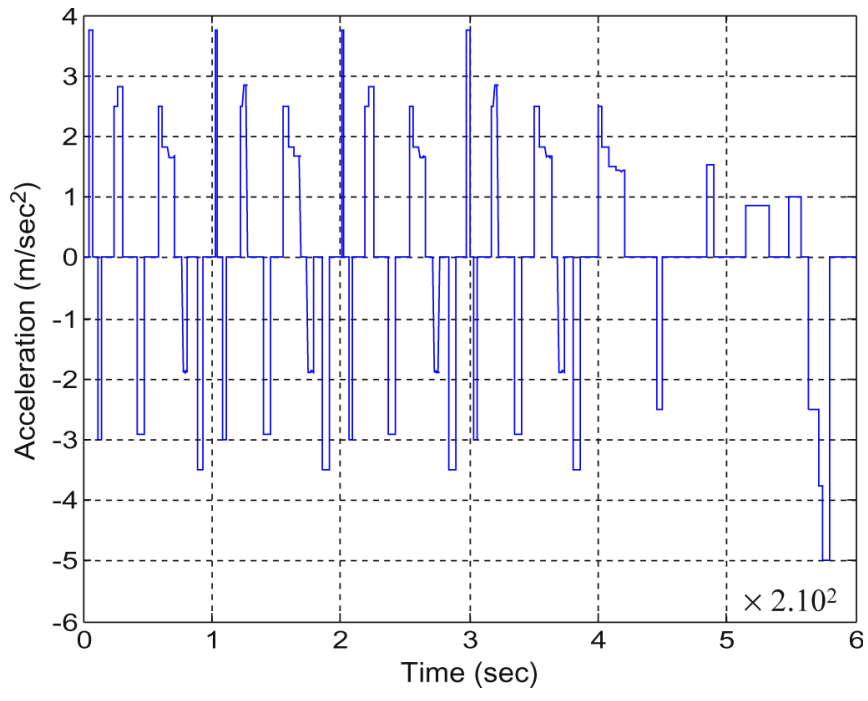

Fig. 12. Acceleration pedal position.

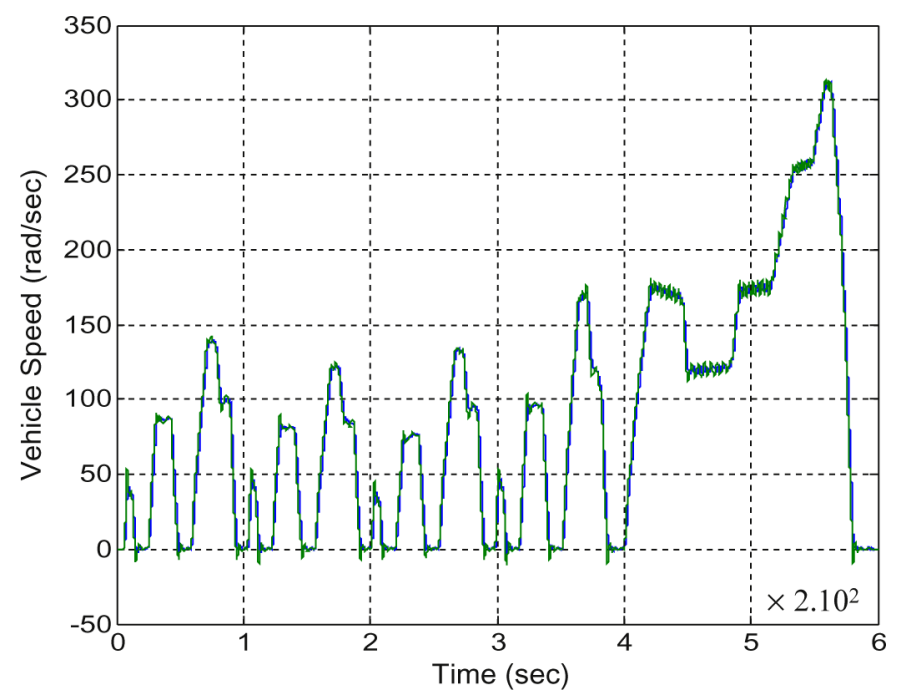

Fig. 13. Estimated and measured vehicle speed.

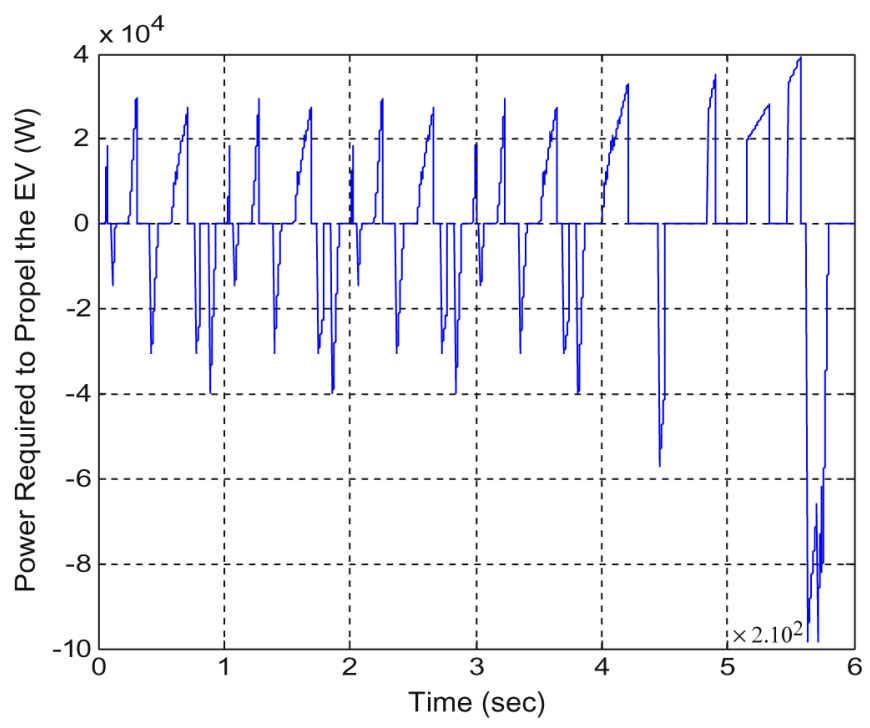

Fig. 14. Power required to propel the EV.

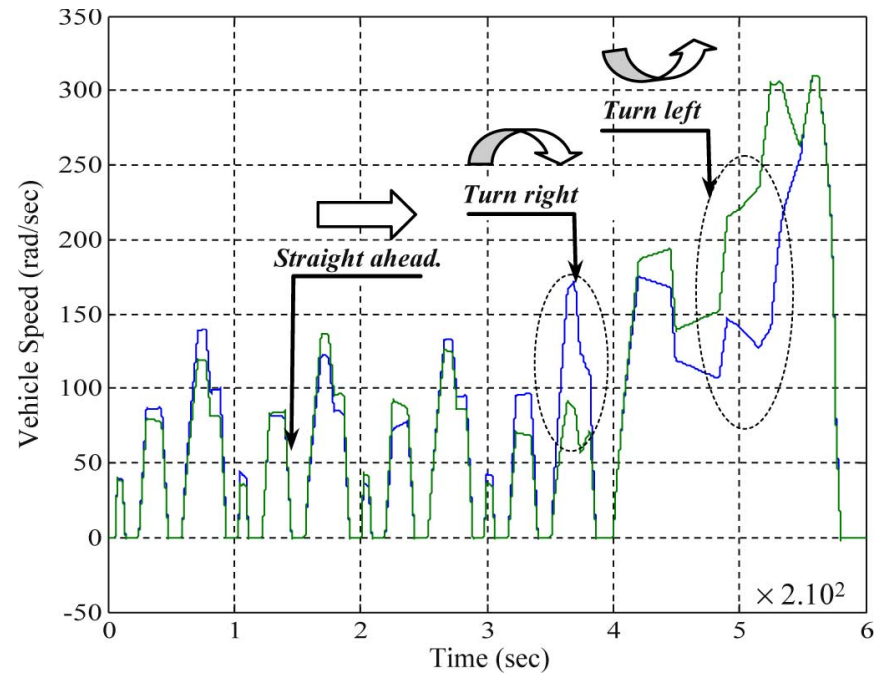

Fig. 15. Vehicle wheels speed.

\section{B. Comparative Study}

Comparative tests with a previously published control technique were conducted [7]. This was done to check the effectiveness of an RNN model for speed estimation of the electric differential.

The electric differential RNN-based control was compared to a sliding mode-based control in the same conditions. Comparing the EV wheel speed results of Fig. 9 (RNN control) to those of Fig. 15 (sliding mode control), it is obvious that the neural network approach is effective particularly during steering at high speeds. Although performances in other cases are quite the same, the proposed control strategy is a sensorless approach and therefore a cost-effective one.

\section{Experimental Validation Perspectives}

The target vehicle for implementation of the proposed control system is a kart as shown by Fig. 16. Adaptations are made to introduce a two independent rear wheels propulsion system using two induction motors [11].

\section{CONCLUSION}

In this paper, a neural network traction control algorithm for an electrical vehicle with two separate wheel drives was proposed. This algorithm is necessary to improve EV steering and stability during trajectory changes. An electrical differential was implemented and accounts for the speed difference between the two wheels when cornering. Moreover, as traction control systems impose very precise knowledge of the vehicle dynamics, a vehicle dynamic model was applied.

Numerical simulations were carried out on an EV propelled by two $37-\mathrm{kW}$ induction motor drives. The test cycle was, in our case, the urban ECE-15 cycle. During traction and regenerative braking, a correlation of traction control with motor performance was realized. The obtained results seem to be very promising. 


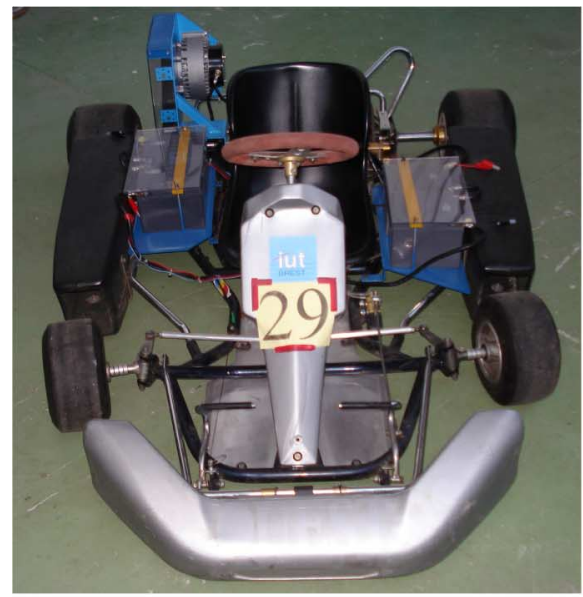

(a)

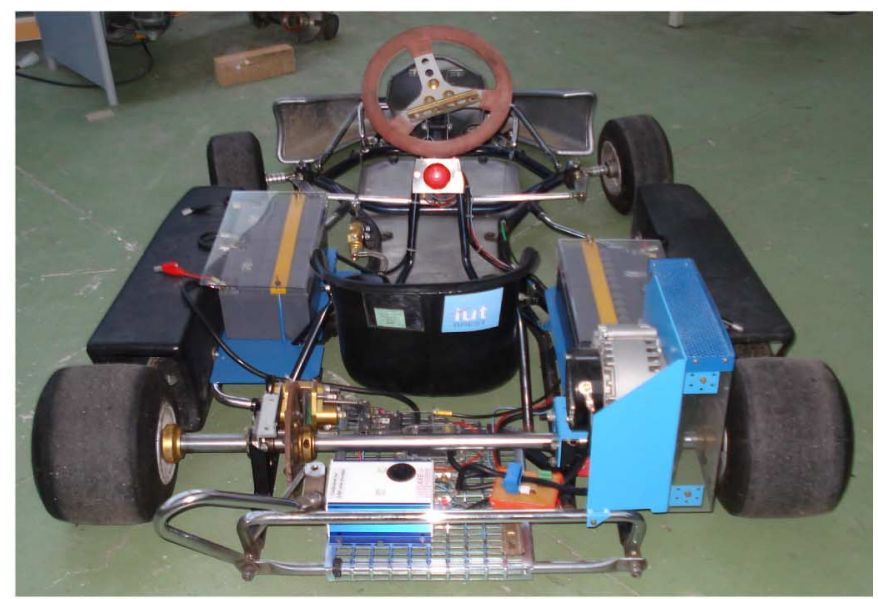

(b)

Fig. 16. Experimental electrical vehicle. (a) Quart front view. (b) Quart rear view.

The RNN speed estimator eliminates the need for an expensive speed transducer with reasonable accuracy. It is shown that the proposed method estimates the speed accurately over the entire range from zero to full speed. Moreover, it has robust speed estimation performance even with step load change or under variable speed operations.

\section{APPENDIX I}

\section{RATED DATA OF THE Simulated INDUCtion Motor}

$37 \mathrm{~kW}, 50 \mathrm{~Hz}, 400 / 230 \mathrm{~V}$

$64 / 111 \mathrm{~A}, 24.17 \mathrm{~N} \cdot \mathrm{m}, 2960 \mathrm{r} / \mathrm{min}$

$R_{\mathrm{S}}=85.1 \mathrm{~m} \Omega, R_{\mathrm{r}}=65.8 \mathrm{~m} \Omega$

$L_{\mathrm{s}}=31.4 \mathrm{mH}, L_{\mathrm{r}}=29.1 \mathrm{mH}, L_{\mathrm{m}}=29.1 \mathrm{mH}$

$J=0.23 \mathrm{~kg} \cdot \mathrm{m}^{2}$.

\section{APPENDIX II}

\section{EV Mechanical and Aerodynamic Parameters}

$m=1540 \mathrm{~kg}$ (two $70 \mathrm{~kg}$ passengers), $A=1.8 \mathrm{~m}^{2}, r=0.3 \mathrm{~m}$

$$
\mu_{\mathrm{rr} 1}=0.0055, \mu_{\mathrm{rr} 2}=0.056, C_{\mathrm{ad}}=0.19, G=104, \eta_{\mathrm{g}}=0.95
$$$$
T=57.2 \mathrm{~N} \cdot \mathrm{m} \text { (stall torque), } v_{0}=4.155 \mathrm{~m} / \mathrm{s}
$$$$
g=9.81 \mathrm{~m} / \mathrm{s}^{2}, \rho=0.23 \mathrm{~kg} / \mathrm{m}^{3} \text {. }
$$

\section{REFERENCES}

[1] C. C. Chan et al., "Electric vehicles charge forward," IEEE Power Energy Mag., vol. 2, no. 6, pp. 24-33, Nov./Dec. 2004.

[2] C. C. Chan, "The state of the art of electric and hybrid vehicles," Proc. IEEE, vol. 90, no. 2, pp. 247-275, Feb. 2002.

[3] M. E. H. Benbouzid et al., "Advanced fault-tolerant control of inductionmotor drives for EV/HEV traction applications: From conventional to modern and intelligent control techniques," IEEE Trans. Veh. Technol., vol. 56, no. 2, pp. 519-528, Mar. 2007.
[4] N. Mutoh et al., "Electric braking control methods for electric vehicles with independently driven front and rear wheels," IEEE Trans. Ind. Electron., vol. 54, no. 2, pp. 1168-1176, Apr. 2007.

[5] N. Mutoh et al., "Driving characteristics of an electric vehicle system with independently driven front and rear wheels," IEEE Trans. Ind. Electron., vol. 53, no. 3, pp. 803-813, Jun. 2006.

[6] K. M. Rahman et al., "Application of direct-drive wheel motor for fuel cell electric and hybrid electric vehicle propulsion system," IEEE Trans. Ind. Appl., vol. 42, no. 5, pp. 1185-1192, Sep./Oct. 2006.

[7] A. Haddoun et al., "Sliding mode control of EV electric differential system," in Proc. ICEM, Chania, Greece, Sep. 2006.

[8] S. Gair et al., "Electronic differential with sliding mode controller for a direct wheel drive electric vehicle," in Proc. IEEE ICM, Istanbul, Turkey, Jun. 2004, pp. 98-103.

[9] Y. Hori, "Future vehicle driven by electricity and control-research on four-wheel-motored 'UOT electric march II'," IEEE Trans. Ind. Electron., vol. 51, no. 5, pp. 954-962, Oct. 2004.

[10] G. Tao et al., "A novel driving and control system for direct-wheeldriven electric vehicle," IEEE Trans. Magn., vol. 41, no. 1, pp. 497-500, Jan. 2005.

[11] R. X. Chen et al., "System design consideration for digital wheelchair controller," IEEE Trans. Ind. Electron., vol. 47, no. 4, pp. 898-907, Aug. 2000.

[12] L. Ju-Sang et al., "A neural network model of electric differential system for electric vehicle," in Proc. IEEE IECON, Oct. 2000, vol. 1, pp. 83-88.

[13] A. Haddoun et al., "Analysis, modeling and neural network traction control of an electric vehicle without differential gears," in Proc. IEEE IEMDC, Antalya, Turkey, May 2007, pp. 854-859.

[14] B. K. Bose, "Neural network applications in power electronics and motor drives-An introduction and perspective," IEEE Trans. Ind. Electron., vol. 54, no. 1, pp. 14-33, Feb. 2007.

[15] M. Cirrincione et al., "Control of induction machines by a new neural algorithm: The TLS EXIN neuron," IEEE Trans. Ind. Electron., vol. 54, no. 1, pp. 127-149, Feb. 2007.

[16] M. Cirrincione et al., "Sensorless control of induction motors by reduced order observer with MCA EXIN + based adaptive speed estimation," IEEE Trans. Ind. Electron., vol. 54, no. 1, pp. 150-166, Feb. 2007.

[17] B. Karanayil et al., "Online stator and rotor resistance estimation scheme using artificial neural networks for vector controlled speed sensorless induction motor drive," IEEE Trans. Ind. Electron., vol. 54, no. 1, pp. $167-$ 176, Feb. 2007.

[18] T. Pajchrowski et al., "Application of artificial neural network to robust speed control of servodrive," IEEE Trans. Ind. Electron., vol. 54, no. 1, pp. 200-207, Feb. 2007.

[19] A. Rubaai et al., "Implementation of artificial neural network-based tracking controller for high-performance stepper motor drives," IEEE Trans. Ind. Electron., vol. 54, no. 1, pp. 218-227, Feb. 2007.

[20] S. Jung et al., "Hardware implementation of a real-time neural network controller with a DSP and an FPGA for nonlinear systems," IEEE Trans. Ind. Electron., vol. 54, no. 1, pp. 265-271, Feb. 2007.

[21] F. J. Lin et al., "Recurrent-fuzzy-neural-network-controlled linear induction motor servo drive using genetic algorithms," IEEE Trans. Ind. Electron., vol. 54, no. 3, pp. 1449-1461, Jun. 2007. 
[22] C. M. Lin et al., "Recurrent-neural-network-based adaptive backstepping control for induction servomotors," IEEE Trans. Ind. Electron., vol. 52, no. 6, pp. 1677-1684, Dec. 2005.

[23] M. Wlas et al., "Artificial-neural-network-based sensorless nonlinear control of induction motors," IEEE Trans. Energy Convers., vol. 20, no. 3, pp. 520-528, Sep. 2005.

[24] Z. Zhu et al., "Electrical machines and drives for electric, hybrid, and fuel cell vehicles," Proc. IEEE, vol. 95, no. 4, pp. 764-765, Apr. 2007.

[25] M. Zeraoulia et al., "Electric motor drive selection issues for HEV propulsion systems: A comparative study," IEEE Trans. Veh. Technol., vol. 55, no. 6, pp. 1756-1764, Nov. 2006

[26] F. Khoucha et al., "A minimization of speed ripple of sensorless DTC for controlled induction motors used in electric vehicles," in Proc. IEEE IECON, Paris, France, Nov. 2006, pp. 1339-1344.

[27] A. Haddoun et al., "A loss-minimization DTC scheme for EV induction motors," IEEE Trans. Veh. Technol., vol. 56, no. 1, pp. 81-88, Jan. 2007.

[28] A. B. Proca et al., "Sliding-mode flux observer with online rotor parameter estimation for induction motors," IEEE Trans. Ind. Electron., vol. 54, no. 2, pp. 716-723, Apr. 2007.

[29] R. E. Colyer et al., "Comparison of steering geometries for multi-wheeled vehicles by modelling and simulation," in Proc. IEEE CDC, Dec. 1998, vol. 3, pp. 3131-3133.

[30] M. André et al., in Proc. Driving Cycles Emissions Meas. Under Eur. Conditions, 1995, pp. 193-205. SAE Paper No. 950926.

[31] A. Cordeiro et al., "Sensorless speed control system for an electric vehicle without mechanical differential gear," in Proc. IEEE MELECON, Malaga, Spain, May 2006, pp. 1174-1177.

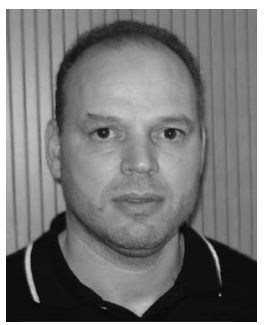

Abdelhakim Haddoun was born in Constantine, Algeria, in 1967. He received the B.Sc. and M.Sc. degrees in electrical engineering from the University of Batna, Batna, Algeria, in 1993 and 1999, respectively. He is currently working toward the Ph.D. degree, focusing on electric vehicle control and power management, in University of Batna.

Since 2000, he has been with the Department of Electrical Engineering, University of Oum El Bouaghi, Oum El Bouaghi, Algeria, as a Teaching Assistant. He is also currently with the Laboratoire Brestois de Mécanique et des Systèmes, University of Western Brittany, Brest, France.

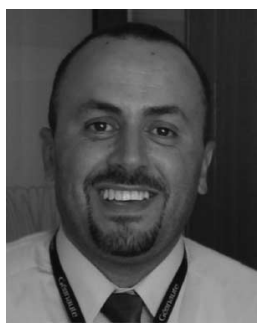

Mohamed El Hachemi Benbouzid (S'92-M'95SM'98) was born in Batna, Algeria, in 1968. He received the B.Sc. degree in electrical engineering from the University of Batna, Batna, Algeria, in 1990, the M.Sc. and Ph.D. degrees in electrical and computer engineering from the National Polytechnic Institute of Grenoble, Grenoble, France, in 1991 and 1994, respectively, and the Habilitation à Diriger des Recherches degree from the University of Picardie "Jules Verne," Amiens, France, in 2000.

After receiving the Ph.D. degree, he joined the Professional Institute of Amiens, University of Picardie "Jules Verne," where he was an Associate Professor of electrical and computer engineering. Since September 2004, he has been with the Laboratoire Brestois de Mecanique et des Systemes, University of Western Brittany, Brest, France, as a Professor of electrical engineering. His research interests and experience include analysis, design, and control of electric machines, variable-speed drives for traction and propulsion applications, and fault diagnosis of electric machines.

Prof. Benbouzid is a Senior Member of the IEEE Power Engineering, Industrial Electronics, Industry Applications, Power Electronics, and Vehicular Technology Societies. He is an Associate Editor for the IEEE TRANSACTIONS ON ENERGY CONVERSION, IEEE TRANSACTIONS ON INDUSTRIAL ELECTRONICS, IEEE TRANSACTIONS ON VEHICUlar TECHNOLOGY, and IEEE/ASME TRANSACTIONS ON MECHATRONICS.

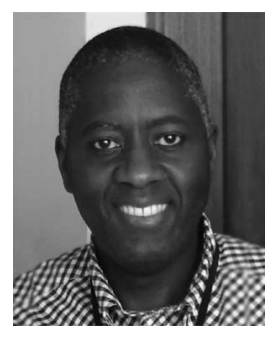

Demba Diallo (M'99-SM'05) was born in Dakar, Senegal, in 1966. He received the M.Sc. and Ph.D. degrees in electrical and computer engineering from the National Polytechnic Institute of Grenoble, Grenoble, France, in 1990 and 1993, respectively, and the "Habilitation á Diriger des Recherches" degree from the University of Paris Sud P11, Gif-Sur-Yvette, France, in 2005.

From 1994 to 1999, he was a Research Engineer with the Laboratoire d'Electrotechnique de Grenoble, Grenoble, where he worked on electrical drives and active filters (hardware and software). In 1999, he was with the University of Picardie "Jules Verne," Amiens, France, as an Associate Professor of electrical engineering. In September 2004, he was with the University Institute of Technology of Cachan, University of Paris Sud P11, as an Associate Professor of electrical engineering. He is currently with the Laboratoire de Génie Electrique de Paris, Ecole Superieure d'Electricite, University Pierre and Marie Curie P6 and University of Paris Sud P11, Gif-Sur-Yvette, France. His current research interests include advanced control techniques and diagnosis in the field of ac drives.

Dr. Diallo is a Senior Member of the IEEE Industry Applications, Vehicular Technology and Control Systems Societies. He is an Associate Editor for the IEEE TRANSACTIONS ON VEHICULAR TECHNOLOGY.

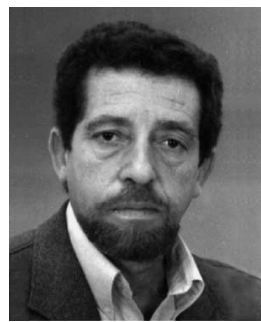

Rachid Abdessemed was born in Batna, Algeria, in 1951. He received the M.Sc. and Ph.D. degrees in electrical engineering, from Kiev Polytechnic Institute, Kiev, Ukraine, in 1978 and 1982, respectively.

He has been working for more than eighteen years at the University of Batna, Batna, Algeria, where he is a Professor in the Electrical Engineering Department. Currently, he is the Director of the Electrical Engineering Laboratory. His current area of research includes design and control of induction machines, reliability, magnetic bearings, and renewable energy.

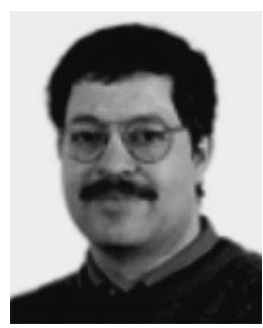

Jamel Ghouili was born in Ghardimaou, Tunisia, in 1962. He received the B.Sc., M.Sc., and Ph.D. degrees from the University of Québec at Trois-Rivières, Canada, in 1986, 1998, and 2004, respectively.

$\mathrm{He}$ is currently Professor at the University of Moncton, Moncton, Canada. His main research interests include power converters, ac drives, DSP and field-programmable gate array control, sensorless control, electric and hybrid electric vehicle drives, fuzzy logic and neural network applications in power

electronics and drives.

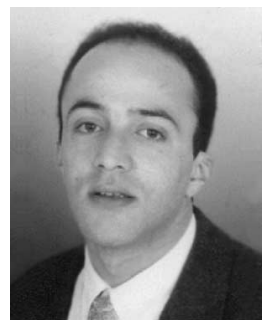

Kamel Srairi was born in Batna, Algeria, in 1967. $\mathrm{He}$ received the B.Sc. degree in electrical engineering from the University of Batna, Batna, Algeria, in 1991, the M.Sc. degree in electrical and computer engineering from the National Polytechnic Institute of Grenoble, Grenoble, France, in 1992, and the Ph.D. degree in electrical and computer engineering from the University of Nantes, Nantes, France, in 1996.

After graduation, he was with the University of Biskra, Biskra, Algeria, where he is a Professor in the Electrical Engineering Department. His main research interests include analysis, design, and control of electric machines. 